\title{
Diagnostic Approaches towards Camelpox Disease
}

\author{
Weledegbrial G. Aregawi ${ }^{\star}$ and Philimon T. Feyissa
}

Ethiopian Institute of Agricultural Research, Werer Agricultural Research Center, Addis Ababa, Ethiopia

${ }^{*}$ Corresponding author: Weledegbrial G. Aregawi, Ethiopian Institute of Agricultural Research, Werer Agricultural Research Center, Addis Ababa, Ethiopia, E-mail: weldedr77@gmail.com

Citation: Weledegbrial G. Aregawi, Philimon T. Feyissa (2016) Diagnostic Approaches towards Camelpox Disease. J Vet Sci Anim Husb 4(3): 303

Received Date: August 26, 2016 Accepted Date: November 28, 2016 Published Date: November 30, 2016

\begin{abstract}
Camelpox is routinely diagnosed based on clinical signs, pathological findings and cellular and molecular assays. Tentative diagnosis can be made based on clinical signs and pox lesions, but will confuse with other diseases, such as contagious ecthyma, papillomatosis and reaction to insect bites. Identification of the agent and antibody detection from serum samples can be used for the differential diagnosis of the disease. Different complementary test methods have been developed for the diagnosis of Camelpox disease. The choice of the test method depends on the purpose of the investigation and the availability of the test methods at a time. Generally isolation and identification of the virus using transmission electron microscopy TEM, Immunohistochemistry, cell cultures and molecular techniques (PCR and LAMP assays) are advised for the confirmation of clinical cases. On the other hand serological tests are valuable for secondary confirmatory testing. The basic principles, comparative advantages and disadvantages of the different diagnostic techniques of camelpox diseases are described in this review.
\end{abstract}

Keywords: Camel; Camelpox; Diagnosis

\section{Introduction}

Pox and pox-like diseases of camels are a group of exanthematous skin conditions that have become increasingly important economically [1]. The diseases may be caused by three distinct viruses: Orthopoxvirus cameli (camelpox), papillomavirus (camel papillomatosis) and parapoxvirus (camel contagious ecthyma) [2]. Camelpox is one of the most common important infectious and contagious viral diseases diagnosed in the old-world camelids, including Camelus dromedaries (dromedary camel) and Camelus bactrianus (Bactrian camel) [3-5].

Camelpox occurs in almost every country in which camel husbandry is practiced apart from the introduced dromedary camel in Australia and tylopods (llama and related species) in South America. The disease was initially described in Punjab, India, in 1909 [5]. Subsequently, outbreaks have been reported in the Middle East (Bahrain, Iran, Iraq, Oman, Saudi Arabia, Syria, United Arab Emirates and Yemen), in Asia (Afghanistan and Pakistan), in Africa (Algeria, Egypt, Ethiopia, Kenya, Mauritania, Morocco, Niger, Somalia and Sudan) and in the southern parts of Russia and India [6-8]. The disease is endemic in these countries and a pattern of sporadic outbreaks occurs with a rise in the seasonal incidence usually during the rainy season $[5,9,10]$. Antibody prevalence of the diseases ranges from 9.8 to $100 \%$ depending on vaccination and outbreak history of the herds [3,4,11-13].

Camelpox is the most important cause of severe economic losses [3,14]. To herdsmen, it is a well-known and feared disease [3]. Its considerable economic importance is due to the high morbidity, a relatively high mortality in younger animals, loss of condition in all ages, reduced milk production in lactating ones and abortion in pregnant camels $[3,13,15]$. In addition, the appearance of camelpox in herds may favor secondary infections from other circulating diseases from which camels might die [7]. The mortality rate in adult animals is between 5\% and $28 \%$ and in young animals between $25 \%$ and $100 \%$ [6]. The disease mostly affects young calves aged 2-3 years in a herd with fatal severe form (generalized form) causing high mortality occasionally due to waning of acquired immunity after 5-8 months [16]. Existence of the disease in developing countries leads to trade restriction of camels and their byproducts [17]. Camelpox is also important because of its possible zoonotic problem $[3,18,19]$. The Office Internationale des Epizooties (OIE), World Organization for Animal Health, lists camelpox as a reportable disease [20].Considering the economic importance of the disease and the virus spreads through contaminated environments, an improved diagnostic and control methods would be of enormous importance to diminish the virus from circulating in the camel herd [17].

Camelpox is routinely diagnosed based on clinical signs, pathological findings and cellular and molecular assays. Complementary techniques such as transmission electron microscopy (TEM), cell culture isolation, immunohistochemistry, demonstration of 
neutralizing antibodies, PCR and LAMP assays are developed and advised for camelpox diagnosis. For each of these techniques, exhaustive descriptions on sample preparations, storage and test procedure have been provided elsewhere $[8,21,22]$. The objective of this review is therefore to describe the basic principles, application and comparative advantages and disadvantages of the currently available diagnostic methods of camelpox disease.

\section{Diagnosis of Camelpox}

\section{Clinical Signs}

Clinical manifestations of camelpox range from inapparent and mild local infections, confined to the skin, to moderate and less common severe systemic infections, possibly reflecting differences between the strains of camelpox or differences in the immune status of the animals [5]. Skin lesions appear 1-3 days after the onset of fever, starting as erythematous macules, developing into papules and vesicles, and later turning into pustules. Crusts develop on the ruptured pustules. The lesion is usually localized in skin but occasionally, it leads to generalized form. The later form is frequently seen in young animals aged $2-3$ years in a herd associated with weaning and poor nutrition [23]. In the systemic form, affected animals may show anorexia, salivation, lacrimation and mucopurulent nasal discharge and diarrhoea. Pregnant females may abort [13,15,24].

Tentative diagnosis of camelpox can be made based on clinical signs and pox lesions. However, clinical signs of the disease are often indistinguishable from other diseases, such as contagious ecthyma, papillomatosis and reaction to insect bites [2,25]. Infection with papillomavirus can lead to localized pox-like lesions and may be misdiagnosed as a pox disease [1,26]. Simultaneous infections with both ortho- and parapox viruses have also been described [3,4,10,27]. Definitive diagnosis of camelpox must, therefore, be based on laboratory-based diagnostic tests [3,5].

\section{Transmission Electron Microscopy (TEM)}

TEM is a reliable and rapid method to demonstrate camelpox virus in scabs or tissue samples $[7,8,28]$. This technique enables laboratory confirmation of camelpox through the demonstration of the characteristic brick-shaped orthopoxvirions which is distinct from ovoid-shaped parapoxviruses, the etiological agent of camel contagious ecthyma (Orf) [17,29].

Currently, it is the fastest and best method for distinguishing clinical cases of camelpox and orf caused by camelpox and parapox viruses, respectively, although the viruses can be differentiated by serological techniques and by PCR $[6,8,17]$. However, the method required a relatively high concentration of virus in the sample for positive diagnosis and camelpox virus cannot be differentiated from other Orthopoxvirus (OPV) species [7,8]. The technique is also complex, required high skills to operate electron microscopy and not usually available for veterinarians in the field services [1].

\section{Immunohistochemistry}

Immunohistochemistry for the detection of the infectious agent of camelpox is a relatively fast method and can be used instead of electron microscopy [16]. The camelpox antigen can be identified in infected scabs and tissues using this technique [5,25]. In addition, paraffin-embedded samples can be stored for a long period, enabling future epidemiological and retrospective studies [17]. It is based on the use of monoclonal antibody directed against the epitope A 1 of the orthopoxvirus fusion protein [30,31]. However, immunohistochemistry couldn't differentiate OPV members unless specific monoclonal antibodies are used [32]. Polyclonal antibody can also be used however almost any polyclonal antibody against vaccinia virus is likely to produce reasonable results in this test because of the wide homology between vaccinia and camelpox viruses [16,17].

\section{Virus isolation}

Cell cultures and embryonated chicken eggs are the most useful techniques that can be considered for CMLV isolation [17]. Camelpox virus can be propagated in a large variety cell cultures including the following cell lines: Vero (transformed green monkey kidney), MA-104 (African green monkey kidney), BHK (baby hamster kidney), and Dubca (transformed camel skin fibroblasts) as well as primary cell cultures including lamb testis, lamb kidney, camel embryonic kidney, calf kidney, and chicken embryo fibroblast [8,17]. However, Vero, MA-104 or Dubca cells, in which the virus replicates easily are generally preferred [21]. Blood, serum and homogenized tissue samples can be used to infect cell cultures. Cultures should be monitored for characteristic plaque-type cytopathic effects (CPE) for 10-12 days. However, depending on the virus concentration, plaque-type cytopathic effects can be appeared at one day post-infection [7]. CPE includes the formation of multinucleated syncytia, rounding, ballooning, cell detachment, multinucleated giant cell formation and syncytia with degenerative changes [23].

Camelpox virus can also be isolated on the chorioallantoic membrane (CAM) of 11 to 13 day old embryonating chicken eggs [33]. The eggs should be incubated at $37^{\circ} \mathrm{C}$ and the CAM examined for the presence of characteristic pock lesions. A dense, greyishwhite pocks, flat in shape, with sizes varying between 0.5 and $1.5 \mathrm{~mm}$ diameters are demonstrated after five days of incubation on the CAM [8]. On the other hand, characteristic long, opaque, white proliferative (tigroid) pock lesions have been produced when Vero cell-adapted virus was inoculated onto CAM [34]. However, it is important to consider that the pocks produced by variola virus (VARV) and CMLV in this system are indistinguishable and identity of the causative agent as CMLV must be confirmed by 
TEM, PCR and/or sequencing [22,35]. Camelpox virus does not cause death in inoculated embryonated chicken eggs [17]. The maximum temperature for the formation of pock lesions is $38.5^{\circ} \mathrm{C}$ degrees. If the eggs are incubated at $34.5^{\circ} \mathrm{C}$, the pocks are flatter and a haemorrhagic centre may develop [36].

\section{Serological tests}

A battery of serological tests including haemagglutination (HA), haemagglutination inhibition, virus neutralization test (VNT), indirect ELISA, complement fixation, and fluorescent antibody tests/assays are available for the detection of antibody to CMLV [23]. VNT and ELISA are the most commonly used and sensitive tests. VNT test is based on a reaction between the virus and specific antibody in the test serum. Virus and products containing a neutralizing antibody were mixed under appropriate conditions and then inoculated into cell culture. The presence of unneutralized virus was detected by plaque formation (cytopathic effect). A loss of infectivity was caused by interference by the bound antibody with any of the steps leading to the release of the viral genome from the host cells including attachment, infection, or viral release. On the other hand, ELISA is developed for the detection of total IgG and IgM antibodies to camelpox virus in camel sera and for identifying the seroreactive antigens of the virus. It is a simple method which can successfully be applied for retrospective and also for epidemiological investigations. The test is more sensitive than virus neutralization (VNT) [3].

All the viruses in the genus Orthopoxvirus cross-react serologically. However, within the genus only camelpox virus can cause poxlike lesions in camels. Interestingly, parapox and camelpox viruses do not cross-react each other and so infections of camelpox and camel orf can be distinguished serologically [3]. Most of the conventional serological tests are very time- and labour-consuming, which makes them not suitable for primary diagnosis. However, serological tests are a valuable tool for the purposes of screening population freedom from infection, determination of prevalence of infection and retrospective epidemiological studies in those areas where vaccination against camelpox is not practised [8]. Poxvirus antibodies can be detected in animal sera much more frequently than isolation of the virus from clinical samples [37]. In addition, serological tests are important for surveillances, evaluation of new vaccines and to determine post-vaccination immune status in individual animals or populations.

\section{Polymerase Chain Reaction (PCR)}

Since the advent of PCR, insufficiencies in the quantity of DNA were no longer a limitation in diagnostic procedures [38]. PCR method has also been adopted for the detection of camelpox virus DNA and it is rapid and sensitive method which can detect even a few copies of viral DNA from the clinical samples [1]. DNA can be extracted from cell culture samples and clinical material using numerous commercial kits. A reliable and low-cost two-step extraction procedure has been developed for isolating CMLV DNA from skin samples [25]. The PCR assays available to identify CMLV are based on the detection of different target genes using different specific oligonucleotides/primers.

The PCR techniques targeting A-type inclusion protein (ATIP gene) and Haemagglutinin (HA) gene are generic (genus specific) PCR assays that enables the differentiation of OPV species by producing amplicons of different sizes [39,40]. The ATIP gene-based PCR for example produces a PCR product size of $881 \mathrm{bp}$, which is specific for the camelpox virus whereas HA gene-specific PCR yields a product of $1100 \mathrm{bp}[39,41]$. An extra step consisting of a $B g l \mathrm{II}$ or XbaI restriction digestion allows the unequivocal identification of the virus species $[39,42]$. The HA- PCR amplicon TaqI restriction fragment length polymorphism (RFLP) permits to differentiate between OPV species, but species-specific primers within the HA open reading frame (ORF) of OPVs have also been described [40].

Differentitation of camelpox from other orthopoxvirus (OPV) and parapoxvirus infections by the use of restriction enzyme analysis (REA) needs virus isolation involving tedious and laborious cell culture methods [43]. As a result, species-specific (CMLV) single PCR methods such as Tumor Necrosis Factor-binding protein Receptor-II (TNFR-II) gene has been developed as a quick diagnostic tools to confirm CMLV infection. An amplicon of 270 bp specific to CMLV can be amplified using the TNFR-II gene [17]. A PCR assay targeting the encoding ankyrin repeat protein (C18L gene) has also been developed, to specifically identify CMLV and to differentiate it from other OPVs, capripoxviruses and parapoxviruses. C18L gene yields a specific amplicon of 243 bp in CMLV suspected cases with a sensitivity limit as low as $0.4 \mathrm{ng}$ of viral DNA [44].

For routine diagnosis of a virus of diverse origin, PCR using specific primers designed on the basis of two different genes are highly preferable to avoid false-negative results [17]. As a result, a further duplex PCR based on the C18L and DNA polymerase (DNA pol) genes for specific and rapid detection and differentiation of CMLV from buffalopox virus (BPXV) has also been developed $[44,45]$. These are much more appropriate assays than the generic PCR method for the simultaneous detection and differentiation of CMLV with avoiding an extra step of restriction analysis [7]. The standardized duplex PCR, using a specific set of primers in a single reaction, yields both DNA pol (96 bp) and C18L (243 bp) gene products in CMLV samples, and only a 96-bp amplicon in other OPVs, such as BPXV [17].

As an improvement over conventional PCR approaches, the real-time PCR techniques targeting A36R gene using fluorescence resonance energy transfer (FRET) method have been developed [4]. Similarly, the real-time PCR targeting A13L, rpo18 and viral early transcription factor (VETF) genes using melting curve analysis have been in use for rapid, highly sensitive and specific de- 
tection and quantitation of CMLV and other related OPVs. Recently, C18L gene based real-time PCR based on either SYBR green chemistry or TaqMan hydrolysis probe have also been optimized for specific detection of CMLV in clinical samples [23,44,46,47].

Regardless of the application of PCR for the diagnosis of CMLV with an excellent sensitivity and specificity, it is not commonly used for large scale epidemiological studies because it requires very expensive sophisticated equipment's and skilled personnel. Further, they are not suitable for on-spot detection at field situations or primitive clinical laboratories particularly in developing countries [42].

\section{Loop Mediated Isothermal Amplification (LAMP) Assay}

LAMP is a rapid, accurate, simple and cost-effective novel nucleic acid amplification method under isothermal conditions (60-65 ${ }^{\circ} \mathrm{C}$ ), with great potential application in developing countries for diagnosis without requiring sophisticated equipments and skilled personnel [48]. The LAMP since its first report by Notomi and his coworkers, it has been used widely for the diagnosis of various diseases [49].

LAMP assay based on the highly conserved region of ankyrin repeat protein gene $(C 18 L)$, which is specific only for CMLV, has been developed for the diagnosis of CMLV and evaluated using field clinical samples $[42,44]$. The amplicon size of the LAMP product is 198 bp. The amplified LAMP product can identified by agarose gel electrophoresis and subsequent direct visualization under UV light or observation by naked eye for the presence of turbidity and color change following the addition of SYBR Green I dye and hydroxy naphthol blue (HNB) [42]. This assay appears to be potential as rapid and sensitive diagnostic tool for its application in less equipped rural diagnostics laboratory settings in developing countries.

\section{Conclusion}

For appropriate diagnosis of camelpox, field veterinarians needs an accurate, sensitive, specific, rapid and relatively simple diagnostic method. Over this period, complementary diagnostic techniques such as transmission electron microscopy (TEM), cell culture isolation, immunohistochemistry, demonstration of neutralizing antibodies (serology), PCR and LAMP assays have been developed for camelpox diagnosis. TEM is a quick but less sensitive technique whereas virus isolation and identification is a sensitive method, but not rapid. Virus isolation in cell culture detects only live virus particles, and therefore particles that have been inactivated during processing of scabs or transportation to the laboratory may not be detected. PCR is a fast sensitive and specific method but the equipment may not always be available in all laboratories. Serological tests are valuable tools for large scale epidemiological studies but not suitable for primary confirmatory diagnosis. LAMP comparing in particular to the PCR method, is a rapid, accurate, simple and cost-effective detection method with practical applicability in developing countries where camelpox is enzootic. However currently only limited studies are conducted on the development of camelpox specific LAMP primers. Therefore the development and large scale field evaluation of species specific LAMP primers should be the next aim in the improvement of molecular based detection of camelpox.

\section{References}

1. Nagarajan G, Swami SK, Dahiya SS, Sivakumar G, Narnaware SD, et al. (2011) Sequence analysis of topoisomerase gene of pseudocowpoxvirus isolates from camels (Camelus dromedaries). Virus Res 158: 277-80.

2. Munz E (1992) Pox and pox-like diseases in camels. In: Allen WR., Higgins AJ, Mayhew LG, Snow DH, Wade JF (Editors), Proceedings of the $1^{\text {st }}$ International Camel Conference, R and W Publications Limited, Newmarket, 43-6.

3. Azwai SM, Carter SD, Woldehiwet Z, Wernery U (1996) Serology of Orthopoxvirus cameli infection in dromedary camels: analysis by ELISA and western blotting. Comp Immunol Microbiol Infect Dis 19: 65-78.

4. Feffer M, Meyer H, Wernery U, Kaaden OR (1996) Comparison of camelpox viruses isolated in Dubai. Vet Microbiol 49: 135-46.

5. Wernery U, Kaaden OR (2002) Infectious diseases in camelids. Blackwell Berlin 176-87.

6. Mayer A, Czerny CP (1990) Chapter 4, Camelpox Virus. In: Virus Infections of Vertebrates: Virus Infections of Ruminants. Elsevier Science Publisher B.V., Amsterdam, The Netherlands 19-22.

7. Duraffour S, Meyer H, Andrei G, Snoeck R (2011) Camelpox virus. Antivir Res 92: 167-86.

8. OIE (2014a) Camelpox. Terrestrial Manual. Office International des Epizooties, Paris, France 1-14.

9. Khalafalla AI, Ali YH (2007) Observations on risk factors associated with some camel viral diseases. Montpellier France 101-5.

10. Megersa B (2010) An epidemiological study of major camel diseases in the Borana lowland, Southern Ethiopia. DCG Report No. 58, Drylands Cooperation Group, Oslo 1-62.

11. Khalafalla AI, Mohamed MEM, Agab H (1998) Serological survey in camels of the Sudan for prevalence of antibodies to camelpox virus using ELISA technique. J Camel Pract Res 5: 197-200.

12. Housawi FMT (2007) Screening of domestic ruminants sera for the presence of anti-camel pox virus neutralizing antibodies. Assiut Vet Med J 53: 101-5.

13. Mahmoud MA, Abo-Elnag TR, Osman WA, Bassiouny AI, Goda AS (2012) Epidemiology and Characterization of Camel Poxvirus in Northwest Costal Area of Egypt. Global Veterinaria 9: 738-44.

14. Fenner F, Wittek R, Dumbell KR (1989) The Orthopoxviruses. Academic press, New York, 100-2.

15. Al Zi'abi O, Nishikawa H, Meyer H (2007) The first outbreak of camelpox in Syria. J Vet Med Sci 69: 541-3. 
16. Nothelfer HB, Wernery U, Czerny CP (1995) Camel pox: antigen detection within skin lesions -Immunohistochemistry as a simple method of etiological diagnosis. J Camel Pract Res 2: 119-21.

17. Bhanuprakash V, Prabhu M, Venkatesan G, Balamurugan V, Hosamani M, et al. (2010) Camelpox: epidemiology, diagnosis and control measures. Expert Review Anti Infect Ther 8: 1187-201.

18. Kriz B (1982) A study of camelpox in Somalia. J Comp Pathol 92: 1-8.

19. Bera BC, Shanmugasundaram K, Barua S, Venkatesan G, Virmani N, et al. (2011) Zoonotic cases of camelpox infection in India. Vet Microbiol 152: 29-38.

20. OIE (2014b) OIE-Listed diseases, infections and infestations in force in 2014. Office International des Epizooties.

21. Pfeffer M, Wernery U, Kaaden OR, Meyer H (1998) Diagnostic procedures for poxvirus infections in camelids. J Camel Pract Res 5: 189-95.

22. Elliot H, Tuppurainen E (2010) Camelpox. Manual of Diagnostic Tests and Vaccines for Terrestrial Animals 2010: 1177-84.

23. Balamurugan V, Venkatesan G, Bhanuprakas V, Singh RK (2013) Camelpox, an emerging orthopox viral disease. Indian J Virol 24: 295-305.

24. Khalafalla AI, Mohamed MEH (1996) Clinical and epizootiological features of camelpox in Eastern Sudan. J Camel Pract Res 3: 99-102.

25. Yousif AA, Al Naeem AA, Al Ali MA (2010) Rapid non-enzymatic extraction method for isolating PCR-quality camelpox virus DNA from skin. J Virol Methods 169: $138-42$.

26. Munz E, Moallin ASM, Mahnel H, Reimann M (1990) Camel papillomatosis in Somalia. J Vet Med B 37: 191-6.

27. Renner-Muller ICE, Meyer H, Munz E (1995) Characterization of camelpox virus isolates from Africa and Asia. Vet Microbial 45: 371-81.

28. Salem SAH, Shemies OA, Mahmoud Nahed A, Arafa AA (2008) Isolation and Molecular Characterization of Camel Pox Virus. Egypt J Comp Path and Clinic Path 21: 306-18.

29. Damon I (2007) Poxviruses. In Fields Virology ( $5^{\text {th }}$ edn), Lippincot Williams and Wilkins, Baltimore, United States.

30. Czerny CP, Mahnel H (1990) Structural and functional analysis of orthopoxvirus epitopes with neutralising monoclonal antibodies. J General Virol 71: 2341-53. 31. Czerny CP, Johann S, Hoelzle L, Meyer H (1994) Epitope detection in the envelope of intracellular naked orthopoxviruses and identification of encoding genes. Virol 200: 764-77.

32. Guarner J, Zaki SR (2006) Histopathology and immunohistochemistry in the diagnosis of bioterrorism agents. J Histochem Cytochem 54: 3-11.

33. Sheikh Ali HM, Nimir AH, Khalafalla AI (2009) Growth characteristic of Camel pox and Vaccinia viruses in embryonated eggs and cell culture. Trop Anim Health Prod 41: 393-6.

34. Marodam V, Nagendrakumar SB, Tanwar VK, Thiagarajan D, Reddy GS, et al. (2006) Isolation and identification of camelpox virus. Indian J Anim Sci 76: 32627.

35. Baxby D (1972) Smallpox-like viruses from camels in Iran. Lancet 2: 1063-5.

36. Tantawi HH, Saban MS, Reda IM, El-Dahaby H (1974) Camelpox virus in Egypt I - Isolation and Characterization. Bull Epizoot Dis Africa 22: 315-9.

37. Marennikova SS (1975) The results of examinations of wildlife monkeys for the presence of antibodies and viruses of the pox group. Vopr Virusol 3: 321-6.

38. Viljoen GJ, Nel LH, Crowther JR (2005) Molecular Diagnostic PCR Handbook. Springer Netherlands 3-11.

39. Meyer H, Pfeffer M, Rziha HJ (1994) Sequence alterations within and downstream of the A-type inclusion protein genes allow differentiation of Orthopoxvirus species by polymerase chain reaction. J Gen Virol 75: 1975-81.

40. Ropp SL, Jin Q, Knight JC, Massung RF, Esposito JJ (1995) PCR strategy for identification and differentiation of small pox and other orthopoxviruses. J Clin Microbiol 33: 2069-76.

41. Damaso CR, Esposito JJ, Condit RC, Moussatche N (2000) An emergent poxvirus from humans and cattle in Rio de Janeiro state: Cantagalo virus may derive from Brazilian small pox vaccine. Virology 277: 439-49.

42. Meyer H, Ropp SL, Esposito JJ (1997) Gene for A-type inclusion body protein is useful for a polymerase chain reaction assay to differentiate orthopoxviruses. J Virol Methods 64: 217-21.

43. Venkatesan G, Bhanuprakash V, Balamurugan V, Singh RK, Pandey AB (2012a) Development of loop-mediated isothermal amplification assay for specific and rapid detection of camelpox virus in clinical samples. J Virol Methods 183: 34-9.

44. Balamurugan V, Bhanuprakash V, Hosamani M, Jayappa KD, Venkatesan G, et al. (2009) A polymerase chain reaction strategy for the diagnosis of camelpox. J Vet Diagn Invest 21: 231-7.

45. Singh RK, Balamurugan V, Hosamani M, Kallesh DJ, Bhanuprakash V (2008) Sequence analysis of C18L gene of Buffalopox virus: PCR strategy for specific detection and its differentiation from orthopoxviruses. J Virol Methods 154: 146-53.

46. Nitsche A, Ellerbrok H, Pauli G (2004) Detection of orthopoxvirus DNA by real- time PCR and variola virus DNA by melting analysis. J Clin Microbiol 42: 1207-13.

47. Venkatesan G, Bhanuprakash V, Balamurugan V, Prabhu M, Pandey AB (2012b) TaqMan hydrolysis probe based real time PCR for detection and quantitation of camelpox virus in skin scabs. J Virol Methods 181: 192-6.

48. Notomi T, Okayama H, Masubuchi H, Yonekawa T, Watanabe AN, et al. (2000) Loop-mediated isothermal amplification of DNA. Nucleic Acid Res 28: E63. 49. Dhama K, Karthik K, Chakraborty S, Tiwari R, Kapoor S, et al. (2014) Loop-mediated Isothermal Amplification of DNA (LAMP): A New Diagnostic Tool Lights the World of Diagnosis of Animal and Human Pathogens: A Review. Pakistan J Biol Sci 17: 151-66. 


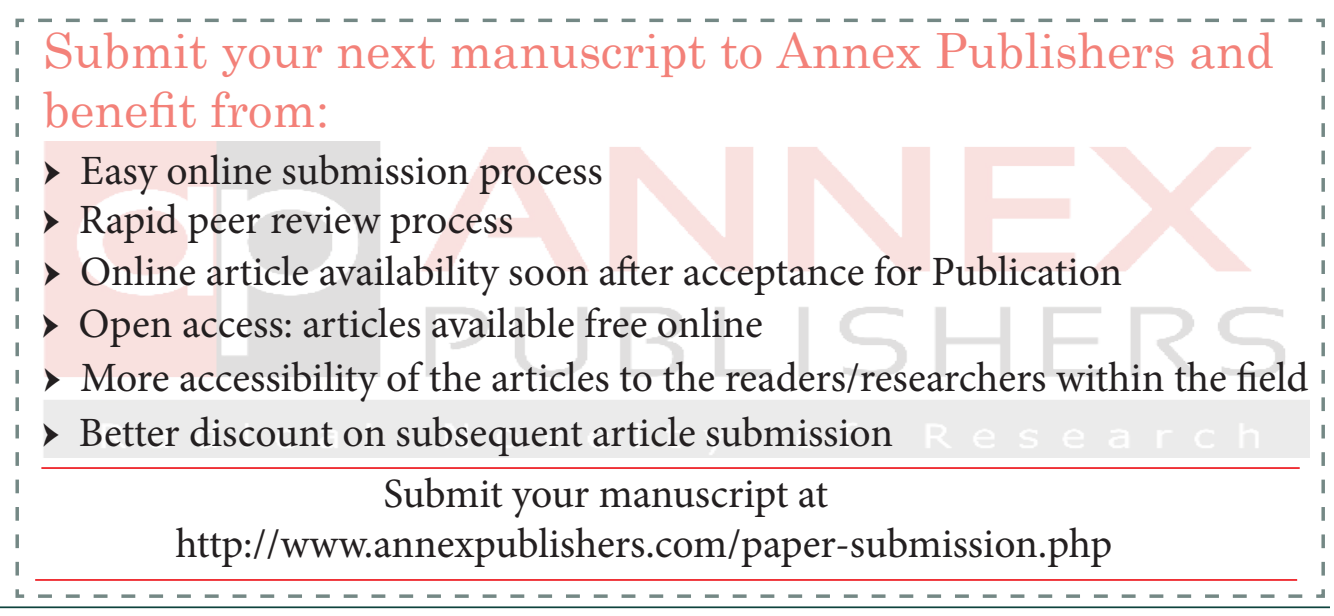

